\title{
Corrigendum: Synthesis and Cytotoxic Activity of Novel Indole Derivatives and Their in silico Screening on Spike Glycoprotein of SARS-CoV-2
}

\author{
Perumal Gobinath ${ }^{1}$, Ponnusamy Packialakshmi ${ }^{1}$, Kaliappillai Vijayakumar ${ }^{2}$, \\ Magda H. Abdellattif ${ }^{3}$, Mohd Shahbaaz ${ }^{4,5}$, Akbar Idhayadhulla ${ }^{1}$ and \\ Radhakrishnan Surendrakumar ${ }^{1 *}$
}

${ }^{1} P G$ \& Research, Department of Chemistry, Nehru Memorial College (Affiliated Bharathidasan University), Puthanampatti, India, ${ }^{2}$ Department of Chemistry, M. Kumarasamy College of Enginnering, Karur, India, ${ }^{3}$ Department of Chemistry, College of Science, Deanship of Scientific Research, Taif University, Taif, Saudi Arabia, ${ }^{4}$ South African Medical Research Council Bioinformatics Unit, South African National Bioinformatics Institute, University of the Western Cape, Cape Town, South Africa, ${ }^{5}$ Laboratory of Computational Modeling of Drugs, South Ural State University, Chelyabinsk, Russia

Keywords: indole, Mannich base, cytotoxic activity, COVID-19, spike protein

\section{A Corrigendum on}

\section{OPEN ACCESS}

Approved by:

Frontiers Editorial Office

Frontiers Media SA, Switzerland

*Correspondence: Radhakrishnan Surendrakumar surendrakumar@nmc.ac.in

Specialty section:

This article was submitted to

Molecular Diagnostics and Therapeutics,

a section of the journal Frontiers in Molecular Biosciences

Received: 28 May 2021 Accepted: 30 June 2021 Published: 05 August 2021

Citation:

Gobinath P, Packialakshmi P, Vijayakumar K, Abdellattif MH, Shahbaaz $M$, Idhayadhulla $A$ and Surendrakumar $R$ (2021) Corrigendum: Synthesis and Cytotoxic Activity of Novel Indole Derivatives and

Their in silico Screening on Spike

Glycoprotein of SARS-CoV-2.

Front. Mol. Biosci. 8:716238.

doi: 10.3389/fmolb.2021.716238
Synthesis and Cytotoxic Activity of Novel Indole Derivatives and Their in silico Screening on Spike Glycoprotein of SARS-CoV-2

by Gobinath, P., Packialakshmi, P., Vijayakumar, K, Abdellattif, M. H., Shahbaaz, M., Idhayadhulla, A., and Surendrakumar, R. (2021). Front. Mol. Biosci. 8:637989. doi: 10.3389/fmolb.2021.637989

The authors Kaliappillai Vijayakumar, Magda H. Abdellattif, Mohd Shahbaaz were not included in the published article and the authors Daoud Ali, Saud Alarifi, and Amal Alotaibi were mistakenly included in the author list. The author list has been corrected throughout the article and in the Author Contributions statement. In addition, the funding information was incorrect and has been amended to include funding for Magda H. Abdellattif. The corrected Author Contributions, Funding and Acknowledgments statements appears below.

The authors apologize for this error and state that this does not change the scientific conclusions of the article in any way. The original article has been updated.

\section{AUTHOR CONTRIBUTIONS}

PG: Organic compounds preparation; PP: Preparation of synthetic compound and chemical data analysis; KV: Manuscript editing; MA: Validation; MS: Molecular docking analysis; AI: All kinds of spectral analysis; RS: Investigation and writing original draft preparation through the contributions of all authors. All the authors contributed to the article and approved the submitted version.

\section{FUNDING}

MA thankfully acknowledges the Taif University researcher supporting project Number TURSP/91, Taif University, Taif, Saudi Arabia. 


\section{ACKNOWLEDGMENTS}

We wish to thank Nehru Memorial College (Affiliated Bharathidasan University), Puthanampatti, India, for taking GC-MS spectra and providing necessary facilities. We wish to thank Tamil Nadu Government for providing DST-FIST fund.

Publisher's Note: All claims expressed in this article are solely those of the authors and do not necessarily represent those of their affiliated organizations, or those of the publisher, the editors and the reviewers. Any product that may be evaluated in this article, or claim that may be made by its manufacturer, is not guaranteed or endorsed by the publisher.

Copyright (๑ 2021 Gobinath, Packialakshmi, Vijayakumar, Abdellattif, Shahbaaz, Idhayadhulla and Surendrakumar. This is an open-access article distributed under the terms of the Creative Commons Attribution License (CC BY). The use, distribution or reproduction in other forums is permitted, provided the original author(s) and the copyright owner(s) are credited and that the original publication in this journal is cited, in accordance with accepted academic practice. No use, distribution or reproduction is permitted which does not comply with these terms. 